\title{
Substrate oxidation differences between high- and low-intensity exercise are compensated over 24 hours in obese men.
}

Citation for published version (APA):

Saris, W. H., \& Schrauwen, P. (2004). Substrate oxidation differences between high- and low-intensity exercise are compensated over 24 hours in obese men. International Journal of Obesity, 28(6), 759-65. https://doi.org/10.1038/sj.ijo.0802631

Document status and date:

Published: 01/01/2004

DOI:

10.1038/sj.ijo.0802631

Document Version:

Publisher's PDF, also known as Version of record

Please check the document version of this publication:

- A submitted manuscript is the version of the article upon submission and before peer-review. There can be important differences between the submitted version and the official published version of record.

People interested in the research are advised to contact the author for the final version of the publication, or visit the DOI to the publisher's website.

- The final author version and the galley proof are versions of the publication after peer review.

- The final published version features the final layout of the paper including the volume, issue and page numbers.

Link to publication

\footnotetext{
General rights rights.

- You may freely distribute the URL identifying the publication in the public portal. please follow below link for the End User Agreement:

www.umlib.nl/taverne-license

Take down policy

If you believe that this document breaches copyright please contact us at:

repository@maastrichtuniversity.nl

providing details and we will investigate your claim.
}

Copyright and moral rights for the publications made accessible in the public portal are retained by the authors and/or other copyright owners and it is a condition of accessing publications that users recognise and abide by the legal requirements associated with these

- Users may download and print one copy of any publication from the public portal for the purpose of private study or research.

- You may not further distribute the material or use it for any profit-making activity or commercial gain

If the publication is distributed under the terms of Article 25fa of the Dutch Copyright Act, indicated by the "Taverne" license above, 


\title{
Substrate oxidation differences between high- and low-intensity exercise are compensated over 24 hours in obese men
}

\author{
WHM Saris $^{1 *}$ and P Schrauwen ${ }^{1}$ \\ ${ }^{1}$ Nutrition and Toxicology Research Institute Maastricht (NUTRIM), Maastricht University, Maastricht, The Netherlands
}

OBJECTIVE: Exercise has been proposed as a tool for the prevention of obesity. Apart from an effect on energy expenditure, in particular low-intensity (LI) exercise might also influence substrate metabolism in favour of fat oxidation. It is however unclear what is the most beneficial exercise regime for obese people. We therefore studied the effect of either high-intensity (HI) or $\mathrm{LI}$ exercise on $24 \mathrm{~h}$ energy expenditure ( $24 \mathrm{~h} \mathrm{EE}$ ) and substrate metabolism.

METHODS: Eight healthy obese male volunteers (age: $38 \pm 1 \mathrm{y}, \mathrm{BMl}: 31 \pm 1 \mathrm{~kg} / \mathrm{m}^{2}, W_{\max }: 235 \pm 16 \mathrm{~W}$ ) stayed in the respiration chamber for two nights and the day in-between. In the chamber they cycled either at a $\mathrm{HI}$ (three times 30 min in a interval protocol $\left(2.5 \mathrm{~min} 80 / 50 \% W_{\max }\right)$ ) or LI (three times $60 \mathrm{~min}$ continuously at $38 \% W_{\max }$ ) protocol with an equicaloric energy expenditure. In the chamber subjects were fed in energy balance (37/48/15\% of energy as fat/carbohydrate/protein).

RESULTS: The $24 \mathrm{~h}$ EE was not significantly different between protocols. In both protocols, sleeping metabolic rate (SMR) was elevated after the exercise (average $+6.7 \%$ ). The $24 \mathrm{~h}$ respiratory quotient ( $24 \mathrm{~h}$ RQ) was not different between protocols. During exercise, RQ was higher in the $\mathrm{HI}$ compared to the $\mathrm{LI}$ protocol $(0.93 \mathrm{vs} 0.91$ resp., $P<0.05)$, whereas in the postexercise period RQ tended to be lower in the $\mathrm{HI}$ compared to the $\mathrm{LI}$ protocol $(P=0.06)$.

CONCLUSION: $24 \mathrm{~h}$ EE is not differently affected by $\mathrm{HI}$ or $\mathrm{LI}$ exercise in obese men. Similarly, the differences in $\mathrm{HI}$ and $\mathrm{LI}$ exercise, RQ are compensated postexercise leading to similar substrate oxidation patterns over $24 \mathrm{~h}$ independently of the level of exercise intensity.

International Journal of Obesity (2004) 28, 759-765. doi:10.1038/sj.ijo.0802631

Published online 30 March 2004

Keywords: exercise; exercise intensity; energy metabolism; fat oxidation

\section{Introduction}

Obesity is a well-recognised problem in our Western society and the development of obesity is characterised by a chronic imbalance between energy expenditure and energy intake. This imbalance can be due to both a reduced energy expenditure and/or an excess energy and fat intake. ${ }^{1}$ Therefore, weight-reducing programs often focus on both decreasing energy intake by dietary restrictions, as well as on increasing energy expenditure by means of exercise. ${ }^{2}$ Although the weight loss due to exercise alone is rather small in comparison to restriction of the energy intake, regular exercise appears to be one of the major factors

*Correspondence: Dr WHM Saris, Nutrition and Toxicology Research Institute Maastricht (NUTRIM), Maastricht University, P.O. Box 616, 6200 MD Maastricht, The Netherlands.

E.mail: W.Saris@hb.unimaas.nI

Received 16 September 2003; revised 6 January 2004; accepted 8

February 2004; published online 30 March 2004 determining long-term weight maintenance success. ${ }^{3,4}$ In relation to the energy balance equation, the factor that has the greatest impact on energy expenditure is volume of the work, which is a function of duration and intensity of the exercise. Most of the debate so far has been focussed on the duration of the exercise. In a recent consensus meeting, the current activity guideline for adults of $30 \mathrm{~min}$ of moderate intense activity preferable all days of the week was challenged. ${ }^{5}$ There is compeling evidence that the prevention of weight regain in formerly obese individuals requires $60-90$ min of moderate intensity activity or lesser amounts of vigorous intensity activity. Although definitive data are lacking, it seems likely that moderate intensity activity of approximately $45-60 \mathrm{~min}$ is required to prevent the transition to overweight or obesity.

Even less clear is the role of the intensity of the exercise in relation to body weight control. High-intensity (HI) exercise can favourably impact energy expenditure in a number of ways. First, exercise-related energy expenditure is of course 
higher per time unit and this is enhanced because the exercise efficiency drops with increasing intensity. HI aerobic exercise may increase $24 \mathrm{~h}$ resting metabolic levels. ${ }^{6}$ Although it has been shown that long-term endurance training also increases resting metabolic rate, this effect is mainly due to an increase in fat-free mass. Whether endurance training influences resting metabolic rate after adjustment for body composition is still controversial. Some studies have shown an increase in resting metabolic rate, adjusted for fat-free mass and fat mass, in response to training ${ }^{7-9}$ whereas others found no effect. ${ }^{10-12}$ In contrast to these studies, not much research has been focused on establishing the most beneficial exercise intensity for increasing $24 \mathrm{~h}$ energy expenditure $24 \mathrm{~h}$ EE. Some studies have shown that $\mathrm{HI}$ exercise has a more pronounced effect on postexercise energy expenditure compared to LI exercise, ${ }^{13-15}$ whereas other found no difference, ${ }^{16,17}$ but these studies only measured energy expenditure for several hours after exercise. However, to determine the optimal exercise intensity for the prevention and/or treatment of obesity, $24 \mathrm{~h}$ EE should be considered. Moreover, exercise intensity might not only have an effect on energy metabolism but also on substrate oxidation. This is of particular interest in the prevention of obesity since it has been suggested that in the obese fat oxidation is impaired and that a diminished fat oxidation is a predictor for future weight gain and obesity. ${ }^{18,19}$ Therefore, when dealing with the optimal exercise intensity to prevent weight (re-)gain also the effects on $24 \mathrm{~h}$ substrate oxidation should be taken into account. We have shown that dietary effects on fat oxidation are slow: after the introduction of a high-fat diet, fat oxidation only gradually increased and equalled fat intake after 7 days. ${ }^{20}$ In contrast, we and others have shown that a single exercise bout can rapidly increase fat oxidation for up to $36 \mathrm{~h}$ postexercise in both lean ${ }^{21.22}$ and obese subjects. ${ }^{23}$ Thus, exercise can be helpful in increasing fat oxidation capacity and thereby facilitating weight maintenance and possibly preventing obesity. However, it is still unknown what is the best option for the obese taken into account that people do not like HI exercise

During LI exercise energy is primarily supplied by fat, whereas during $\mathrm{HI}$ exercise the main energy supplier is carbohydrate oxidation, ${ }^{24}$ suggesting that LI exercise would be most beneficial for increasing fat oxidation. On the other hand, HI exercise will deplete glycogen stores, which will lead to increased rates of fat oxidation in the postexercise period. ${ }^{22}$ So far, only two studies have examined the longterm effect of exercise intensity on $24 \mathrm{~h}$ fat oxidation and these studies failed to find a positive effect of $\mathrm{HI}$ exercise on $24 \mathrm{~h}$ fat oxidation, ${ }^{25,26}$ although an increased $24 \mathrm{~h}$ energy expenditure after $\mathrm{HI}$ exercise was found in the study of Treuth et $a l^{25}$ To the best of our knowledge, no controlled studies have been performed that examined the acute effect of exercise intensity on $24 \mathrm{~h}$ energy and substrate metabolism in obese subjects, which is of particular interest since obese subjects are characterised by an impaired fat oxidation capacity. Therefore, the aim of the present study was to study the acute effects of either HI or L.I equicaloric exercise on both $24 \mathrm{~h}$ energy expenditure and substrate oxidation in obese men.

\section{Methods \\ Subjects}

Eight male obese volunteers participated in the study. Their characteristics are shown in Table 1. All subjects were untrained (less than $1 \mathrm{~h} /$ week participating in sport activities) and obese (BMI $>30 \mathrm{~kg} / \mathrm{m}^{2}$ ) males. A medical examination excluded subjects with cardiovascular diseases, diabetes mellitus, asthma or other metabolic diseases. The study was reviewed by the Medical Ethical Committee of the University of Maastricht and all subjects gave their written informed consent.

\section{Experimental design}

Each subject followed two different protocols in random order with 2 weeks in-between. Prior to each protocol subjects were given a diet for consumption at home for 3 days. Each protocol consisted of a $36 \mathrm{~h}$ stay in the respiration chamber. Subjects came to the laboratory on the evening of day 0 (2000) and left the respiration chamber on the morning of day 2 at 0830 . While in the respiration chamber, subjects cycled three times $30 \mathrm{~min}$ at alternatively bouts of $2.5 \mathrm{~min}$ at 80 and $50 \%$ of their maximal work output $\left(W_{\max }\right)$ (HI) or three times $60 \mathrm{~min}$ at $38 \% W_{\max }(\mathrm{LI})$. These exercise bouts were calculated to achieve an similar energy expenditure during both $\mathrm{HI}$ and $\mathrm{LI}$ protocol, assuming similar mechanical efficiency. On the morning of day 2, after the first visit in the respiration chamber, body composition was determined using underwater weighing

\section{Maximal power output and exercise tests}

At 1 week before the experimental protocol each subject performed an incremental exhaustive exercise test on an electronically braked cycle ergometer (Lode Excalibur, Groningen, The Netherlands) to determine maximal oxygen consumption $\left(V \mathrm{O}_{2 \max }\right)$ and maximal power output $\left(W_{\max }\right)$.

Table 1 Subjects' characteristics $(n=8)$

\begin{tabular}{lc}
\hline & mean \pm s.e.m. \\
\hline Age $(y)$ & $38.3 \pm 1.1$ \\
Height $(\mathrm{m})$ & $1.76 \pm 0.02$ \\
Weight $(\mathrm{kg})$ & $96.9 \pm 4.6$ \\
Percent body fat $(\%)$ & $32.3 \pm 1.3$ \\
BMl $\left(\mathrm{kg} / \mathrm{m}^{2}\right)$ & $31.2 \pm 1.3$ \\
Wmax $(\mathrm{w})$ & $235 \pm 16$ \\
$\mathrm{VO}_{2} \max (\mathrm{l} / \mathrm{min})$ & $3.3 \pm 0.2$ \\
\hline
\end{tabular}

$\mathrm{VO}_{2}$ max: maximal oxygen consumption. 
Exercise was performed until voluntary exhaustion or until the subject could no longer maintain a pedal rate of more than $60 \mathrm{rpm}$. Subjects started at $100 \mathrm{~W}$ and work load was increased by $50 \mathrm{~W}$ every $2.5 \mathrm{~min}$. When subjects were approaching exhaustion, as indicated by heart rate and subjective scoring, the increment was reduced to $25 \mathrm{~W}$. In practice, this meant that the last one to three load increments were $25 \mathrm{~W}$. Oxygen consumption and carbon dioxide production were measured continuously using a Sensormedics 2900 metabolic cart (Anaheim, USA). Heart rate was registered continuously using a Polar Sporttester (Kempele, Finland). In each individual $W_{\max }$ was calculated from

$$
W_{\max }=W_{\text {out }}+(t / 150) * \partial W
$$

in which Wout is the highest workload completed by the subject, $t$ is the time (in s) performed on the last workload and $\partial W$ is the final uncompleted load increment.

In the respiration chamber subjects cycled three times (0900, 1300 and 1930). In the LI protocol subjects cycled for $60 \mathrm{~min}$ at $38 \% W_{\max }$. In the $\mathrm{HI}$ protocol subjects cycled for $30 \mathrm{~min}$ at alternatively 80 and $50 \% W_{\max }$ for 2.5 min periods. During the HI protocol all exercise periods were preceded by 5 min warming up at $33 \% W_{\max }$ and were ended by 5 minutes cooling down, also at $33 \% W_{\max }$. In this way total amount of work accomplished in both intensity groups was calculated to be identical.

\section{Diets}

Food intake diaries were filled in during 3 days ( 2 weekdays and one weekend day). Subjects habitual energy and macronutrient intake was determined using 3 days food intake records. Prior to each protocol subjects were given a diet for consumption at home for 3 days. Subjects were given a fixed amount of food (based on their food intake record) and ad libitum access to snacks. Energy requirement on the first day in the respiration chamber was set at 1.55 times sleeping metabolic rate (SMR) as measured during the first night plus an amount of energy equal to the amount of energy expended during the exercise tests. The latter was calculated by assuming a mechanical efficiency of $20 \%$. At the second stay in the respiration chamber energy intake was fixed at the same level as during the first stay. All food was consumed as breakfast, lunch, dinner and two or more snacks per day. Diets consisted of $47 \%$ of energy as carbohydrate, $37 \%$ of energy as fat and $15 \%$ of energy as protein. Energy intake and macronutrient composition of the diets were calculated using the Dutch food composition table. $^{27}$

\section{Procedures}

Body composition. On the morning of day 2 whole-body density was determined by underwater weighing in the fasted state, directly after subjects left the respiration chamber. Body weight was measured with a digital balance accurate to $0.01 \mathrm{~kg}$ (Sauter, type E1200). Lung volume was measured simultaneously with the helium dilution technique using a spirometer (Volugraph 2000, Mijnhardt). Percent body fat was calculated using the equations of Siri. ${ }^{28}$

Indirect calorimetry and physical activity. Oxygen consumption and carbon dioxide production was measured in a whole-room indirect calorimeter, which was described previously. ${ }^{29}$ The respiration chamber is a $14 \mathrm{~m}^{3}$ room furnished with a bed, chair, television, radio, telephone, intercom, wash bowl, and toilet. The room is ventilated with fresh air at a rate of $70-80 \mathrm{l} / \mathrm{min}$. The ventilation rate was measured with a dry gas meter (Schlumberger, type G6, The Netherlands). The concentration of oxygen and carbon dioxide was measured using a paramagnetic $\mathrm{O}_{2}$ analyser (Hartmann \& Braun, type Magnos G6, Germany) and an infrared $\mathrm{CO}_{2}$ analyser (Hartmann \& Braun, type Uras 3G, Germany). Ingoing air was analysed every $15 \mathrm{~min}$ and outgoing air once every $5 \mathrm{~min}$. The gas sample to be measured was selected by a computer that also stored and processed the data. Energy expenditure was calculated from $\mathrm{O}_{2}$ consumption and $\mathrm{CO}_{2}$ production according to the method of Weir. ${ }^{30}$ In the daytime, outside the exercise periods, no sleeping or other exercise was allowed during the stay in the respiration chamber. Therefore, the subjects mainly watched television, read or did some 'bench work'. Spontaneous physical activity of the subjects was monitored by means of a radar system based on the Doppler principle.

Urinary nitrogen excretion. During the stay in the respiration chamber $24 \mathrm{~h}$ urine was collected from 0800 to 0800 . Subjects had to empty the bladder at 0800 so urine produced during the night could be included with the urine sample of the previous day. Samples were collected in containers with $10 \mathrm{ml} \mathrm{H}_{2} \mathrm{SO}_{4}$ to prevent nitrogen loss through evaporation; volume and nitrogen concentration were measured, the latter using a nitrogen analyser (Heraeus, type CHN-ORapid).

The $24 \mathrm{~h}$ EE and substrate oxidation. The $24 \mathrm{~h} \mathrm{EE}$ and $24 \mathrm{~h}$ respiratory quotient (RQ) were calculated from 0800 am to $0800 \mathrm{am}$. SMR was defined as the lowest mean energy expenditure during three subsequent hours between 0000 and 0800 . Energy expenditure during the exercise period was defined as the total energy expended during the three exercise bouts. The postexercise energy expenditure was defined as the total energy expended during the $2 \mathrm{~h}$ after each exercise bout. Carbohydrate, fat and protein oxidation were calculated using $\mathrm{O}_{2}$-consumption, $\mathrm{CO}_{2}$-production and urinary nitrogen losses with the equations of Brouwer. ${ }^{31}$ protein oxidation $(\mathrm{g} /$ day $)=6.25 * \mathrm{~N}$

fat oxidation $(\mathrm{g} /$ day $)=1.718 * V \mathrm{VO}_{2}-1.718 * V \mathrm{CO}_{2}-0.315 * P$ carbohydrate oxidation ( $/$ day) $=4.17 * V \mathrm{CO}_{2}-2.965 *$ $\mathrm{VO}_{2}-0.390 * P$ 
where $N$ is the total nitrogen excreted in urine (g/day), $\mathrm{VO}_{2}$ is the oxygen consumption (l/day), $\mathrm{VCO}_{2}$ is the carbon dioxide production ( $1 /$ day), $P$ is protein oxidation ( $g /$ day).

Statistical analysis. Paired $t$-test were used to test differences in measured variables between protocols. All data are presented as mean \pm s,e.m. and $P<0.05$ was considered as statistical significant.

\section{Results}

The habitual energy intake was $11.7 \pm 1.4 \mathrm{MJ} /$ day. This was achieved by $37 \pm 4 \%$ of energy as fat, $43 \pm 4 \%$ of energy as carbohydrate and $17 \pm 1 \%$ of energy as protein. Maximal power output ( $W_{\max }$ ) was $235 \pm 16 \mathrm{~W}$, and maximal oxygen consumption $\left(V \mathrm{O}_{2 \max }\right)$ was $3.3 \pm 0.21 / \mathrm{min}$.

The $24 \mathrm{H} \mathrm{EE}$ was not significantly different between the LI and HI protocol (Table 2, Figure 1). As there were no differences in energy intake, energy balance was not significantly different between the LI and HI protocol. More important, subjects were in energy balance during both protocols $(-0.07 \pm 0.4$ vs $-0.13 \pm 0.2 \mathrm{MJ} /$ day for $\mathrm{HI}$ and $\mathrm{LI}$ respectively, (Table 2). As was designed, energy expenditure during exercise was equal between $\mathrm{HI}$ and LI (6.17 \pm 0.91 and

Table 2 The 24 h-energy intake, energy expenditure and energy balance as measured in the respiration chamber $n=8$ (mean \pm s.e.m)

\begin{tabular}{lccc}
\hline Protocol & Intake (M) & Expenditure (MI) & Balance (MI) \\
\hline $\mathrm{LI}$ & $16.62 \pm 0.53$ & $16.69 \pm 0.63$ & $-0.07 \pm 0.43$ \\
$\mathrm{HI}$ & $16.62 \pm 0.54$ & $16.75 \pm 0.62$ & $-0.13 \pm 0.21$ \\
\hline
\end{tabular}

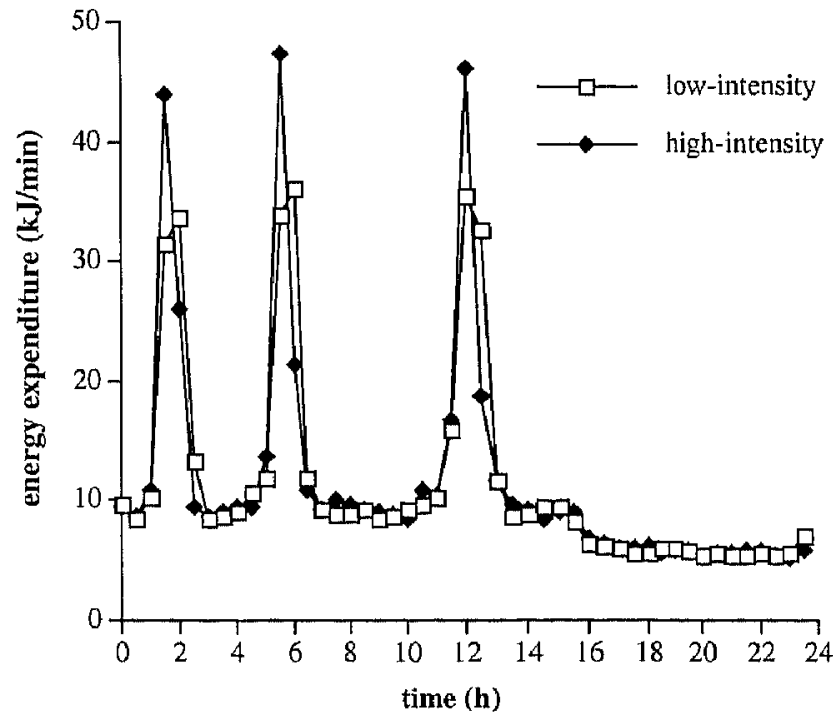

Figure 1 Mean $24 \mathrm{~h}$ EE in the respiration chamber from 0800 on day 1 to 0730 on day 2 for the $\mathrm{LI}$ and $\mathrm{HI}$ protocol $(n=8)$
$6.22 \pm 0.92 \mathrm{MJ}$ respectively). Energy expended during exercise accounted for approximately $38 \%$ of $24 \mathrm{~h}$ EE. Energy expended in the postexercise period was also not significantly different between $\mathrm{HI}$ and $\mathrm{LI}(9.6 \pm 0.4$ vs $9.8 \pm 0.5 \mathrm{KJ} /$ min respectively). SMR was significantly higher during the second night compared to the first night in both protocols $(P<0.05$, Table 3$)$. The within-subject coefficient of variation for SMR was $2.9 \pm 1.5 \%$. Physical activity index $(\mathrm{PAI}=24 \mathrm{H}$ EE/SMR) was not significantly different between the both protocols (Table 3 ).

The $24 \mathrm{~h}$ RQ was not significantly different between HI and LI (Table 4). No significant differences in RQ between HI and LI and between night 1 and 2 were found (Table 4). For this period the within-subject coefficient of variation for RQ was $2.1 \pm 1.8 \%$. Respiration quotient during the exercise period was significantly lower during $\mathrm{LI}$ compared to $\mathrm{HI}$

Table 3 SMR (from 0000-0800) and PAl as measured in the respiration chamber (mean \pm 5.e.m)

\begin{tabular}{lccc}
\hline Protocol & SMR night 1 $(\mathrm{kl} / \mathrm{min})$ & SMR night $2(\mathrm{kl} / \mathrm{min})$ & PAl \\
\hline LI & $5.07 \pm 0.21$ & $5.44 \pm 0.22^{\star}$ & $2.22 \pm 0.05$ \\
HI & $5.20 \pm 0.20$ & $5.53 \pm 0.21^{\star}$ & $2.19 \pm 0.06$ \\
\hline
\end{tabular}

aphysical activity index: $24 \mathrm{~h} \mathrm{EE} / 24 \mathrm{~h}$ SMR. ${ }^{*} p<0.05$ compared to night 1 .

Table $4 \mathrm{RQ}$ as measured in the respiration chamber

\begin{tabular}{lccccc}
\hline Protocol & $24 \mathrm{~h} \mathrm{RQ}$ & RQ night 1 & RQ night 2 & Exercise RQ & Postexercise RQ \\
\hline LI & $0.89 \pm 0.01$ & $0.85 \pm 0.01$ & $0.84 \pm 0.01$ & $0.91 \pm 0.00^{*}$ & $0.90 \pm 0.01^{\dagger}$ \\
$\mathrm{HI}$ & $0.89 \pm 0.01$ & $0.83 \pm 0.01$ & $0.83 \pm 0.01$ & $0.93 \pm 0.01$ & $0.87 \pm 0.02$ \\
\hline$* P<0.05$ & &
\end{tabular}

${ }^{\star} P<0.05$ compared to $\mathrm{HI} .{ }^{\dagger} \mathrm{P}=0.06$ compared to $\mathrm{HI}$.

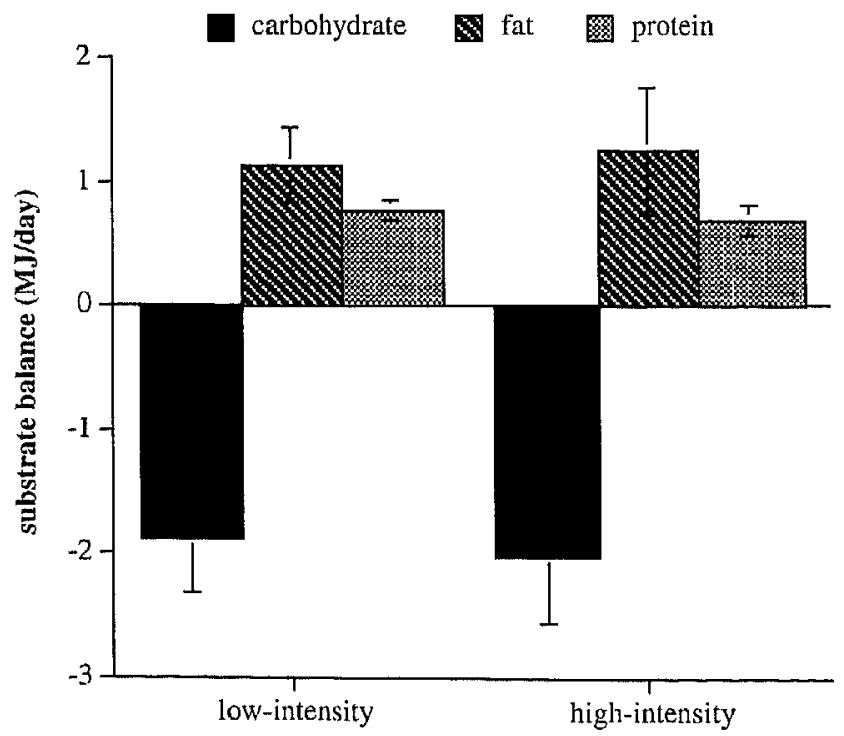

Figure 2 The $24 \mathrm{~h}$ substrate balances (mean + s.e.m.) as measured in the respiration chamber from 0800 on day 1 to 0730 on day 2 for the $\mathrm{LI}$ and $\mathrm{HI}$ protocol 
$(P<0.05)$. In the postexercise period RQ tended to be higher during LI compared to $\mathrm{HI}(P=0.06)$.

$24 \mathrm{~h}$ fat oxidation was not significantly different between $\mathrm{HI}$ and Ll. Fat oxidation was significantly lower than fat intake, resulting in positive fat balances of $33.2 \pm 13.6$ and $30.1 \pm 8.2 \mathrm{~g} /$ day for $\mathrm{HI}$ and LI respectively (Figure 2 ). The $24 \mathrm{~h}$ carbohydrate oxidation was not significantly different between $\mathrm{HI}$ and LI. Carbohydrate oxidation was significantly higher than carbohydrate intake, resulting in negative carbohydrate balances of $-120.1 \pm 32.6$ and $-112.2 \pm 25.6 \mathrm{~g} /$ day for $\mathrm{HI}$ and LI respectively (Figure 2). The $24 \mathrm{~h}$ protein oxidation was also not significantly different between $\mathrm{HI}$ and $\mathrm{LI}$ and protein oxidation was significantly lower than protein intake. This resulted in positive protein balances of $41.3 \pm 7.3$ and $46.3 \pm 4.9 \mathrm{~g} /$ day for HI and LI respectively (Figure 2).

\section{Discussion}

The results of the present study demonstrate that both $24 \mathrm{~h}$ $\mathrm{EE}$ and substrate oxidation are not differently affected by equicaloric HI or LI exercise in obese men. During the LI exercise periods $R Q$ was significantly lower indicating a higher fat oxidation. However, postexercise RQ tended to be lower after the HI exercise periods compared to the LI exercise, indicating a compensating effect on fat oxidation leading to a $24 \mathrm{~h}$ similar substrate oxidation profile.

Since obesity develops due to small differences between energy intake and energy expenditure over prolonged periods of time, physical inactivity has been suggested as an important predictor of weight gain. ${ }^{1,2}$ When considering the treatment of obesity and in particular body weight regain, regular physical activity can overcome the decrease in energy expenditure, which is associated with an initial lower body mass. ${ }^{32}$ Exercise not only increases total energy expenditure due to the extra energy expended during the exercise but also due to an elevated postexercise energy expenditure. Some studies have shown that $\mathrm{HI}$ exercise has a more pronounced effect on postexercise energy expenditure compared to LI exercise, ${ }^{13-15}$ whereas other found no difference. ${ }^{16,17}$ However, these studies only measured energy expenditure for several hours after the exercise bout. Therefore, we used the respiration chamber to study the effect of LI or HI exercise on energy and substrate metabolism, while subjects were fed in perfect energy balance. The latter is of crucial importance since both energy expenditure and especially substrate utilisation can be easily influenced by a positive or negative energy balance, as was observed in the studies of Treuth et al. ${ }^{25,33}$ We found that under energy balance conditions three times of either LI or HI exercise with the same total workload resulted in an increase in SMR during the night following the exercise day. The magnitude of this elevation in SMR was similar after the LI and HI exercise and averaged $0.35 \mathrm{~kJ} / \mathrm{min}(6.7 \%)$. These data are in accordance with the findings of others, showing that an acute bout of exercise increases resting (or sleeping) metabolic rate. ${ }^{21,34}$ Although this elevation in metabolic rate seems to be only minor, the development of obesity is often also characterised by minimal deviations between energy expenditure and energy intake over prolonged pexiods of time. Furthermore, it has been shown that a $10 \%$ lower SMR is a predictor for future weight gain. ${ }^{35}$ Therefore, the effect of exercise on sleeping metabolic rate might be significant in the prevention and/or treatment of obesity, although the amount of exercise in this protocol has to be taken into account. The PAI for both exercise intensities was around 2.2 which is at the upper extreme of the PAI distribution. ${ }^{36}$ This relatively high level of exercise for sedentary obese subjects could certainly have contributed to the positive effect on SMR compared to some of the negative studies in the past, which were at a lower total workload or in trained subjects.

The $24 \mathrm{~h}$ EE was not significantly affected by exercise intensity. This is in contrast to the finding of Treuth et al, ${ }^{25}$ who showed an increased $24 \mathrm{~h}$ EE with HI compared to LI exercise. However, in their study, energy expended during exercise was higher with the $\mathrm{HI}$ protocol, even though similar amounts of work were performed, indicating a reduced mechanical efficiency. ${ }^{25}$ It has indeed been shown that with increasing exercise intensity, mechanical efficiency is reduced, probably due to the increased dependence on inefficient fast-twitch fibres. ${ }^{6,37}$ In our study, in obese subjects, we did not find any difference in total energy expenditure during the exercise bouts, indicating no differences in energy efficiency between the $\mathrm{HI}$ and LI exercise. Furthermore, we found no effect of exercise intensity on postexercise energy expenditure in the present study. Therefore, in accordance with the study of Melanson, ${ }^{26}$ our study shows that exercise intensity does not influence $24 \mathrm{~h}$ EE.

Perhaps more important, apart from an effect on energy metabolism, is the effect of exercise on substrate oxidation. We hypothesised that exercise intensity would differentially influence $24 \mathrm{~h}$ substrate oxidation. It is well known that at low exercise intensities, fat oxidation is responsible for the major part of the energy demands and that with increasing exercise intensity the contribution of carbohydrate oxidation increases. It has been shown that maximal fat oxidation is achieved between 40 and $60 \% W_{\text {max. }}{ }^{24}$ Therefore, LI exercise has been considered the most beneficial for the treatment of obesity. However, LI exercise only has minor influence on postexercise fat oxidation. According to the two-compartment model of Flatt, fat oxidation can be increased by (1) expansion of the adipose tissue mass or (2) maintaining glycogen stores in a lower range. ${ }^{38}$ Regarding the latter, it is well known that HI exercise will lead to reduction of the glycogen stores, and would thus allow for a higher fat oxidation postexercise. Indeed, we recently showed that $24 \mathrm{~h}$ fat oxidation could be increased 1.5 -fold by performing glycogen lowering exercise in both lean ${ }^{22}$ and obese subjects. ${ }^{23}$ In these studies, we found a negative 
Exercise intensity and 24h-substrate oxidation WHM Saris and P Schrauwen

764

correlation between carbohydrate balance during the first $12 \mathrm{~h}$ in a respiration chamber and the subsequent $24 \mathrm{~h}$ fat oxidation. These results illustrate the impact of the glycogen stores on $24 \mathrm{~h}$ fat oxidation. In the present study, we were just underpowered to detect a significant effect on a lower postexercise RQ after $\mathrm{HI}$ exercise. However, the subsequent night RQ as well as the $24 \mathrm{~h} \mathrm{RQ}$ were not different suggesting that the decrease in muscle glycogen in the present study was insufficient to trigger an increase in $24 \mathrm{~h}$ fat oxidation. Therefore, the results indicate that over a relative large range of exercise intensities (up to $80 \% V \mathrm{O}_{2 \max }$ ) $24 \mathrm{~h}$ substrate utilisation after an acute exercise load is not affected. Only at even higher intensity exercise (upto $100 \% V \mathrm{O}_{2 \max }$ ) and with glycogen depletion, an effect on substrate utilisation is observed, as shown by the studies of Schrauwen et al ${ }^{22,23}$ and Treuth et al. ${ }^{25}$ In this context, in our study in the HI exercise protocol subjects exercised only $50 \%$ of the exercised-time at $80 \% V_{2 \max }$, probably to little to result in changes in glycogen levels.

The negative results from this and other well-controlled $24 \mathrm{~h} \mathrm{EE}$ studies ${ }^{26}$ of the effects of acute HI or LI exercise bouts on substrate utilisation seems to be in contrast to the recently published training study of van Aggel et al, ${ }^{39}$ showing a $40 \%$ increase in fat oxidation during exercise (but not at rest) after a $\mathrm{LI}\left(40 \% \mathrm{VO}_{2 \max }\right)$ training protocol compared to a $\mathrm{HI}\left(70 \% V_{2} \mathrm{O}_{2 \max }\right)$ training protocol. Casecontrols studies examining the effect of participation in vigorous physical activities consistently showed a favouring effect of $\mathrm{HI}$ exercise on body fatness, ${ }^{40,41}$ as well as on postprandial fat oxidation. ${ }^{42}$ One possible explanation why in the $24 \mathrm{~h}$ respiration chamber studies, in contrast to training and case-control studies, no effect of exercise intensity on substrate metabolism is observed, might be the acute character of the exercise in the chamber studies. In the $24 \mathrm{~h}$ EE studies, nontrained lean or obese subjects, not habituated to perform such exercise bouts, were studied. Based on the similar results coming out of these studies it seems that the intensity level of an acute exercise bout as such does not contribute to the $24 \mathrm{~h}$ substrate oxidation pattern. Only regular training or daily vigorous physical activity does have an effect on muscle metabolism leading to a higher reliance on fat as energy substrate at a similar level of exercise intensity. ${ }^{2}$ This change in substrate preference is only observed during exercise, most likely since at rest, muscle metabolism already almost completely relies on fat as a substrate. This is an important argument for maintaining exercise adherence over time. ${ }^{43}$ Further well-controlled respiration chamber studies are needed to test whether regular exercising or physical activity at $\mathrm{HI}$ or LI affects $24 \mathrm{~h}$ substrate utilisation.

In conclusion in obese men, both LI and HI exercise increased SMR but no difference in $24 \mathrm{~h}$ EE was observed. Similarly, the differences in $\mathrm{HI}$ and LI exercise RQ was compensated postexercise leading to similar substrate oxidation patterns over $24 \mathrm{~h}$ independently of the level of exercise intensity.
Acknowledgements

We thank Marjolein van Gaalen and Sander van Vught for their assistance in collecting data.

\section{References}

1 Schrauwen $P$, Westerterp KR. The role of high-fat diets and physical activity in the regulation of body weight. Br $/$ Nutr 2000; 84: 417-427.

2 Saris WHM. Physical activity and body weight regulation. In: Bouchard C, Bray GA (eds) Regulation of body weight: Biological and behavorial mechanisms. John Wiley \& Sons Ltd: New York; 1996. pp 135-148.

3 Ballor DL, Keesey RE. A meta-analysis of the factors affecting exercise-induced changes in body mass, fat mass and fat-free mass in males and females. Int J Obes Relat Metab Disord 1991; 15: 71.7-726.

4 van Baak MA, van Mil E, Astrup AV, Finer N, Van Gaal LF, Hilsted J, Kopelman PG, Rossner S, James WP, Saris WH, STORM Study Group. Leisure-time activity is an important determinant of longterm weight maintenance after weightloss in the sibutramine trial on obesity reduction and maintenance (Strom trial). Am I Clin Nutr 2003; 78: 209-214.

5 Saris WHM, Blair SN, van Baak MA, Eaton SB, Davies PSW, Di Pietro L, Fogelholm M, Rissanen A, Schoeller D, Swinburn B, Tremblay $A$, Westerterp $K R$, Wyatt $H$. How much physical activity is enough to prevent unhealthy weight gain? Outcome of the IASO ist Stock Conference and Consensus Statement. Obes Rev 2003; 4: 101-114.

6 Hunter GR, Weinsier RL, Bamman MM, Larson DE. A role for high intensity exercise on energy balance and weight control. Int $J$ Obes Relat Metab Disord 1998; 22: 489-493.

7 Poehlman ET, Melby CL, Bradylak SF, Calles J. Resting metabolic rate and postprandial thermogenesis in highly trained and untrained males. Am J Clin Nutr 1988; 47; 793-798.

8 Tremblay A, Fontaine E, Poehlman ET, Mitchell D, Perron L, Bouchard $C$. The effect of exercise-training on resting metabolic rate in lean and obese moderately obese individuals. Int I Obes Relat Metab Disord 1986; 10: 511-517.

9 Pratley R, Nicklas B, Rubin M, Miller J, Smith A, Smith M, Hurley $B$, Goldberg A. Strength training increases resting metabolic rate and norepinephrine levels in healthy 50- to 65-yr-old men. $/ A p p /$ Physiol 1994; 76: 133-137.

10 Schulz LO, Nyomba BL, Alger S, Anderson TE, Ravussin E, Effect of endurance training on sedentary energy expenditure measured in a respiratory chamber. Am / Physiol Endocrinol Metab 1991; 260: E257-E261.

11 Davis JR, Tagliaferro AR, Kertzer R, Gerardo T, Nichols J, Wheeler J. Variations in dietary-induced thermogenesis and body fatness with aerobic capacity. Eur J Appl Physiol 1983; 50: 319-329.

12 Westerterp KR, Meijer GAL, Schoffelen P, Janssen E. Body mass, body composition and sleeping metabolic rate before, during and after endurance training. Eut J Appl Physiol 1994; 69: 203-208.

13 Gore CJ, Whither RT. The effect of exercise intensity and duration on the oxygen deficit and excess post-exercise oxygen consumption. Eur J Appl Physiol 1990; 60; 169-174.

14 Phelain JF, Reinke E, Harris MA, Melby CL. Postexercise energy expenditure and substrate oxidation in young women resulting from exercise bouts of different intensity. J Am Coll Nutr 1997; 16: $140-146$.

15 Smith J, Naughton $L$. The effects of intensity of exercise on excess postexercise oxygen consumption and energy expenditure in moderately trained men and women. Eur / Appl Physiol 1993; 67; $420-425$.

16 Sedlock DA, Fissinger JA, Melby CL. Effect of exercise intensity and duration on postexercise energy expenditure. Med Sci Sports Exerc 1989; 21: 662-666. 
17 Sedlock DA. Effect of exercise intensity on postexercise energy expenditure in women. Br J Sports Med 1991; 25: 38-40.

18 Astrup A, Buemann B, Christensen NJ, Toubro S. Failure to increase lipid oxidation in response to increasing dietary fat content in formerly obese women. Am / Physiol 1994; 266: E592-E599.

19 Blaak EE, Baak MAv, Kemerink GJ, Pakbiers MTW, Heidendal GAK, Saris WHM. B-Adrenergic stimulation of energy expenditure and forearm skeletal muscle metabolism in lean and obese men. Am J Physiol Endocrinol Metab 1994; 267: E306-E315.

20 Schrauwen P, van Marken Lichternbelt WD, Saris WH, Westerterp KR. Changes in fat oxidation in response to a high-fat diet. $A m$ I Clin Nutr 1997; 66: 276-282.

21 Bielinski R, Schutz Y, Jéquier E. Energy metabolism during the postexercise recovery in man. Am J Clin Nutr 1985; 42: 69-82.

22 Schrauwen P, van Marken Lichtenbelt WD, Saris WH, Westerterp $\mathrm{KR}$. Role of glycogen-lowering exercise in the change of fat oxidation in response to a high-fat diet. Am I Physiol 1997; 273: E623-E629.

23 Schrauwen P, Lichtenbelt WD, Saris WH, Westerterp KR. Fat balance in obese subjects: role of glycogen stores. Am J Pliysiol 1998; 274: E1027-1033.

24 Romijn JA, Coyle EF, Sidossis LS, Gastaldelli A, Horowitz JF Endert E, Wolfe RR. Regulation of endogenous fat and carbohydrate metabolism in relation to exercise intensity and duration. Am / Physiol Endocrinol Metab 1993; 265: E380-E391.

25 Treuth MS, Hunter GR, Williams M. Effects of exercise intensity on 24h-energy expenditure and substrate oxidation. Med $\mathrm{Sc}$ Sports Exerc 1996; 28: 1138-1144.

26 Melanson EL, Sharp TA, Seagle HM, Horton TJ, Donahoo WT, Grunwald GK, Hamilton JT, Hill JO. Effect of exercise intensity on 24-h energy expenditure and nutrient oxidation. / Appl Physiol 2002; 92: 1045-1052.

27 Stichting-Nederlands-Voedingsstoffenbestand. NEVO Tabel, Voorlichtingsbureau voor de voeding, Den Haag, 1993. [in Dutch].

28 Siri WE. The gross composition of the body. Adv Biol Med Physio 1956; 4: 239-280.

29 Schoffelen PF, Westerterp KR, Saris WH, Ten Hoor F. A dualrespiration chamber system with automated calibration. J App! Physiol 1997; 83: 2064-2072.

30 Weir JB. New methods for calculating metabolic rate with special reference to protein metabolism. J Physiol 1949; 109: 1-9.
31 Brouwer E. On simple formulae for calculating the heat expenditure and the quantities of carbohydrate and fat oxidized in metabolism of men and animals, from gaseous exchange (oxygen intake and carbonic acid output) and urine-n. Acta Physiol Pharmacol Neerlandica 1957; 6: 795-802.

32 Saris WHM. Physical inactivity and metabolic factors as predictors of weight gain. Nutr Rev 1996; 54: S110-\$115.

33 Treuth MS, Hunter GR, Weinsier R1, Kell SH. Energy expenditure and substrate utilization in older women after strength training: 24-h calorimeter results. I Appl Physiol 1995; 78: 2140-2146.

34 Bahr R, Ingnes I, Vaage O, Sejersted OM, Newsholme EA. Effect of duration of exercise on excess postexercise $\mathrm{O}_{2}$ consumption. $f$ Appl Physiol 1987; 62: 485-490.

35 Ravussin E, Lillioja S, Knowler WC, Christin L, Freymond D, Abbott WG, Boyce $V$, Howard BV, Bogardus C. Reduced rate of energy expenditure as a risk factor for body-weight gain. $N \mathrm{Engl} J$ Med 1988; 318: $467-472$.

36 Westerterp KR. Alterations in energy balance with exercise, $\mathrm{Am}$ J Clin Nutr 1998; 68: 970S-974S.

37 Gaesser GA, Brooks GA. Muscular efficiency during steady-state exercise: effects of speed and work rate. I Appl Physiol 1975; 38 : 1132-1139.

38 Flatt JP. The difference in the storage capacities for carbohydrate and for fat, and its implications in the regulation of body weight. Ann N Y Acad Sci 1987; 499: 104-123.

39 Van Aggel-Leijssen DP, Saris WH, Wagenmakers AJ, Senden JM, Van Baak MA. Effect of exercise training at different intensities on fat metabolism of obese men. I Appl Pliysiol 2002; 92: 1300-1309.

40 Tremblay A, Despres JP, Leblanc C, Craig CL, Ferris B, Stephens T, Bouchard $C$. Effect of intensity of physical activity on body fatness and fat distribution. Am I Clin Nutr 1990; 51: 153-157.

41 Dionne I, Almeras N, Bouchard C, Tremblay A. The association between vigorous physical activities and fat deposition in male adolescents. Med Sci Sports Exerc 2000; 32: 392-395.

42 Yoshioka M, Doucet E, St-Pierre S, Almeras N, Richard D, Labrie A, Despres JP, Bouchard $C$, Tremblay A. Impact of high-intensity exercise on energy expenditure, lipid oxidation and body fatness. Int I Obes Relat Metab Disord 2001; 25: 332-339

43 Wing RR, Jackicic JM. Changing lifestyle: moving from sedentary to active. In: Bouchard C (ed) Physical activity and obesity. Human Kinetics: Champaign, IL; 2000. pp 372-389. 